\title{
UNCERTAINTY PRINCIPLE FOR THE SPHERICAL MEAN OPERATOR
}

\section{RADOUAn DAHER, ABDElmajid KhadARI AND Slim OMri}

Abstract. The $L^{p}-L^{q}$ version of Miyachi's theorem is proved for the Fourier transform associated with the spherical mean operator.

Mathematics subject classification (2010): Primary: 43A32; secondary: 42B10.

Keywords and phrases: Spherical mean operator, Fourier transform, uncertainty principle, Miyachi's theorem.

\section{REFERENCES}

[1] R. DAHER, On the therems of Hardy and Miyachi theorem for the Jacobi-Dunkl transform, Integral Transforms Spec. Funct., Vol. 18 (2007), Issue 5, 305-311.

[2] J. A. FAWCETT, Inversion of $N$-dimensional spherical means, SIAM. J. Appl. Math. Vol. 45 (1985), 336-341.

[3] H. Helesten And L. E. Anderson, An inverse method for the processing of synthetic aperture radar data, Inverse Problems. Vol. 4 (1987), 111-124.

[4] A. MiYACHI, A generalization of theorem of Hardy, Harmonic Analysis Seminar held at Izunagaoka, Shizuoka-Ken, Japon 1997, 44-51.

[5] M. M. Nessibi, L. T. RACHDi, AND K. TRIMÈCHE, Ranges and inversion formulas for spherical mean operator and its dual, J. Math. Anal. Appl. Vol. 196 (1995), no. 3, 861-884.

[6] S. OMRI, Uncertainty principle in terms of entropy for the spherical mean operator, J. Math. Inequal. Vol. 5 (2010), Issue. 4, 473-490.

[7] A. L. Schwartz, An inversion theorem for Hankel transforms, Proc. Amer. Math. Soc. Vol. 22 (1969), no. 3, 713-717.

[8] G. N. Watson, A treatise on the theory of Bessel functions, 2nd ed., Cambridge Univ. Press., London/New York, 1966. 